\title{
ESTUDOS PRELIMINARES DE OBTENÇÃO DE AGREGADO SINTÉTICO A PARTIR DE BIOMASSA EM REATOR DE LEITO FIXO
}

\author{
D. S. QUARESMA ${ }^{1}$, A. S. S. NEVES ${ }^{1}$, E. N. MACÊDO ${ }^{2}$, J. A. S. SOUZA ${ }^{2}$, P. T. S. BEZERRA ${ }^{3}$ \\ e L. F. S. PEREIRA ${ }^{4}$
}

${ }^{1}$ Universidade Federal do Pará, Programa de Pós- Graduação em Engenharia de Recursos Naturais da Amazônia

${ }^{2}$ Universidade Federal do Pará, Programa de Pós- Graduação em Engenharia de Recursos Naturais da Amazônia, Faculdade de Engenharia Química e Instituto de Tecnologia

${ }^{3}$ Universidade Federal do Pará, Faculdade de Engenharia Química

${ }^{4}$ Universidade Federal do Pará, Programa de Pós-Graduação em Engenharia Química E-mail para contato: danysq@gmail.com

\begin{abstract}
RESUMO- agregados sintéticos de argila são utilizados pela indústria de elementos pré-moldados de concreto armado. Este estudo avalia a obtenção de agregados sintéticos, após sinterização, com o objetivo de aproveitar resíduos industriais, para serem utilizados na construção civil. A cinza volante de caldeira, resíduo gerado a partir da queima de carvão mineral, é utilizada para produção do agregado sintético. Os experimentos foram realizados em um reator vertical de leito fixo para promover a sinterização do material, que deve ocorrer à temperatura acima de $1250^{\circ} \mathrm{C}$, ao longo do reator. Para a produção dos agregados sintéticos confeccionaram-se pelotas em betoneira a partir de uma mistura de argila, cinza volante de caldeira e carvão vegetal, em diferentes granulometrias. O processo é voltado para redução de impactos ambientais, em virtude da capacidade que o material produzido tem em substituir agregados naturais, melhorando a qualidade do concreto.
\end{abstract}

\section{INTRODUÇÃO}

O trabalho de Cabral et al. (2008) mostra que agregados sintéticos de argila vêm sendo largamente utilizados pela indústria de elementos pré-moldados de concreto armado, em todos os tipos de construção civil. Agregado sintético é aquele proveniente da transformação de solo, folhelho argiloso, resíduo silico-aluminoso ou argila, previamente processado, em um material inerte e com resistência mecânica satisfatória para uma determinada finalidade. Essas características são normalmente obtidas através da queima deste material em temperaturas elevadas, com temperaturas superiores a $1100{ }^{\circ} \mathrm{C}$. A qualidade do produto acabado depende fundamentalmente da matéria-prima utilizada, da temperatura de queima e do processo de conformação da massa cerâmica, como normalmente são chamados os solos argilosos destorroados, misturados, umedecidos, laminados que são a base do processo cerâmico.

Tem sido mostrado na literatura de Santos (1989) que a argila é um material natural, terroso, de granulação fina, que adquire, quando umedecido com água, certa plasticidade. Todas as argilas são constituídas por argilominerais, que são compostos quimicamente por 
silicatos hidratados de alumínio e ferro, contendo ainda certo teor de elementos alcalinos e alcalino-terrosos.

Segundo Tancredi (2010) a queima do carvão mineral em caldeiras de uma central termoelétrica gera vapor e produz resíduos durante o processo da combustão do carvão, conhecidas como cinzas. As partículas de cinza tendem a apresentar uma forma esférica, o que confere uma boa plasticidade à massa. A sua composição química contém vários óxidos, sendo que os principais são os óxidos de alumínio, sílica e cálcio, além de outros óxidos em menor proporção que são o titânio, manganês e zinco; sua composição granulométrica estão entre 5 e $200 \mu \mathrm{m}$, com tamanho médio de 30 a $50 \mu \mathrm{m}$ e trata-se de materiais, na sua grande parte, amorfos contendo percentagens muito baixas de componentes cristalinos, constituídos por agulhas finíssimas de mulita.

A grande quantidade de óxido de silício, com teor de 51,71\%, ocasionará posteriormente a formação da camada vítrea, após a reação de sinterização. A camada vítrea corresponde à fase amorfa que compõe o agregado que depende da quantidade de fundente, a qual está diretamente relacionada a propriedades como: porosidade, absorção de água e massa específica aparente.

Os trabalhos de Brindley e Nakahira (1958) mostraram que o material na sinterização deve possuir um teor de vidro suficiente em baixa viscosidade na temperatura de formação, com o intuito de preencher a maioria dos poros e reter os gases formados, através das reações de vitrificação (formação de fase amorfa).

Tem sido mostrado nos trabalhos de Mörtel e Heimstadt (1994) que as reações de vitrificação são responsáveis pela redução dos poros na estrutura dos materiais cerâmicos. Esta etapa da transformação de fase nestes materiais é influenciada diretamente pela redução da viscosidade da fase vítrea, que é favorecida pela presença de metais alcalinos como o sódio e o potássio.

O uso energético da biomassa (fonte renovável) vem sendo valorizado como forma alternativa ao uso de combustíveis fósseis. A biomassa utilizada neste trabalho é o carvão vegetal, proveniente da queima parcial da madeira ou de outra biomassa vegetal, que funciona como combustível sólido no processo de sinterização para formação dos agregados sintéticos.

A reação de sinterização, realizada neste trabalho, ocorre em um reator vertical de leito fixo, também chamado de célula de combustão, no qual ocorre a propagação de uma frente de combustão em um meio poroso reativo (formado por uma mistura de cinza volante de caldeira, carvão vegetal e argila). Segundo Martins (2008), neste caso, a fase sólida reage com a fase gasosa, onde ocorrem diversas reações químicas: pirólise, combustão do residual de carbono e reações de estado sólido. Estas reações de transformação são acompanhadas por mudanças bruscas na estrutura física da fase sólida.

O estudo da reutilização de diversos tipos de rejeitos na produção de agregado sintético é um ganho importante do ponto de vista ambiental e energético, pois através dessa reutilização é possível aproveitar materiais que são descartados em grandes quantidades em outras áreas a baixo custo. 


\subsection{Objetivo}

O objetivo principal deste trabalho é aproveitar resíduos industriais que são gerados em larga escala, como a cinza de carvão mineral (cinza volante de caldeira), utilizando-a em uma mistura de argila e carvão vegetal (biomassa), por meio de sinterização em reator vertical de leito fixo, na qual a biomassa será o combustível sólido da sinterização, para produção de agregado sintético.

\section{MATERIAIS E MÉTODOS}

A cinza volante de caldeira utilizada neste trabalho foi cedida pela HYDROALUNORTE (Alumina do Norte do Brasil S/A). A cinza, como apresenta partículas finamente divididas, não necessita de tratamento prévio e pode ser utilizada diretamente na mistura para confecção das pelotas que posteriormente serão submetidas ao processo de sinterização.

A argila retirada das margens do rio Guamá foi previamente seca a $100^{\circ} \mathrm{C}$ em estufa com recirculação de ar durante $24 \mathrm{~h}$ e posteriormente desagregada em moinho de bolas por 30 minutos, deixando este material com o aspecto de pó. $\mathrm{O}$ carvão vegetal obtido comercialmente recebeu o mesmo pré-tratamento realizado com a argila para ser utilizado na mistura das pelotas.

A mistura das matérias-primas é realizada em moinho de bolas para promover a homogeneização durante 30 minutos. Após essa etapa, a mistura é colocada em uma betoneira que por meio de sua movimentação as pelotas eram formadas com adição de $23 \%$ de água, de forma gradativa, e apresentaram tamanhos variados, conforme mostra a Figura 1.

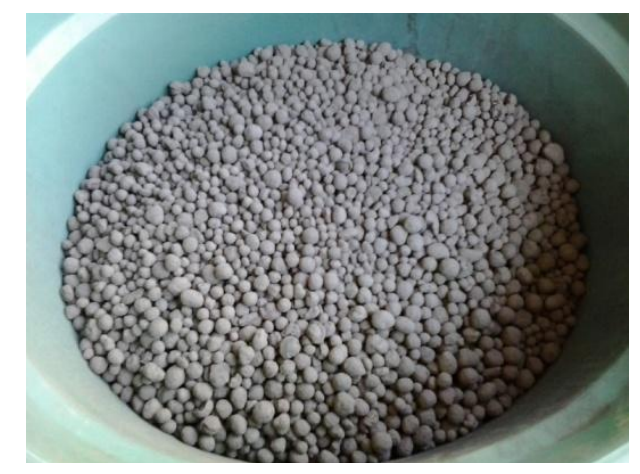

Figura 1- Pelotas formadas dentro da betoneira.

Os experimentos de sinterização foram realizados com $20 \%$ de pelotas e $80 \%$ de carvão classificados preenchendo o leito de sinterização. A composição da mistura dos materiais foi de $40 \%$ de cinza, $30 \%$ de argila e $30 \%$ de carvão. No entanto, houve variação na granulometria destes materiais, conforme pode ser observado na Tabela 1. 
Tabela 1 - Experimentos de sinterização

\begin{tabular}{ccc}
\hline Experimentos & Preenchimento do leito & Granulometria (Gr) \\
\hline 1 & $20 \%$ de Pelotas (P) e & $4 \mathrm{~mm} \leq \mathrm{Gr}<7,93 \mathrm{~mm}(\mathrm{P}) \mathrm{e}$ \\
& $80 \%$ de Carvão (C) & $1,70 \mathrm{~mm} \leq \mathrm{Gr}<4 \mathrm{~mm}(\mathrm{C})$ \\
& $20 \%$ de Pelotas (P) e & $8 \mathrm{~mm} \leq \mathrm{Gr}<11 \mathrm{~mm}(\mathrm{P}) \mathrm{e}$ \\
2 & $80 \%$ de Carvão (C) & $4 \mathrm{~mm} \leq \mathrm{Gr}<8 \mathrm{~mm}(\mathrm{C})$ \\
& $20 \%$ de Pelotas (P) e & $5,66 \mathrm{~mm} \leq \mathrm{Gr}<9,52 \mathrm{~mm}(\mathrm{P}) \mathrm{e}$ \\
3 & $80 \%$ de Carvão (C) & $3,36 \mathrm{~mm} \leq \mathrm{Gr}<5,66 \mathrm{~mm}(\mathrm{C})$ \\
& $20 \%$ de Pelotas (P) e & $10 \mathrm{~mm} \leq \mathrm{Gr}<13 \mathrm{~mm}(\mathrm{P}) \mathrm{e}$ \\
& $80 \%$ de Carvão (C) & $1,70 \mathrm{~mm} \leq \mathrm{Gr}<4 \mathrm{~mm}(\mathrm{C})$ \\
\hline
\end{tabular}

Em seguida, as pelotas foram colocadas em estufa na temperatura de $100^{\circ} \mathrm{C}$ durante $24 \mathrm{~h}$ e após secagem foram classificadas de acordo com sua faixa granulométrica. Em seguida o material classificado foi sinterizado em um reator vertical de leito fixo, conforme a Figura 2.

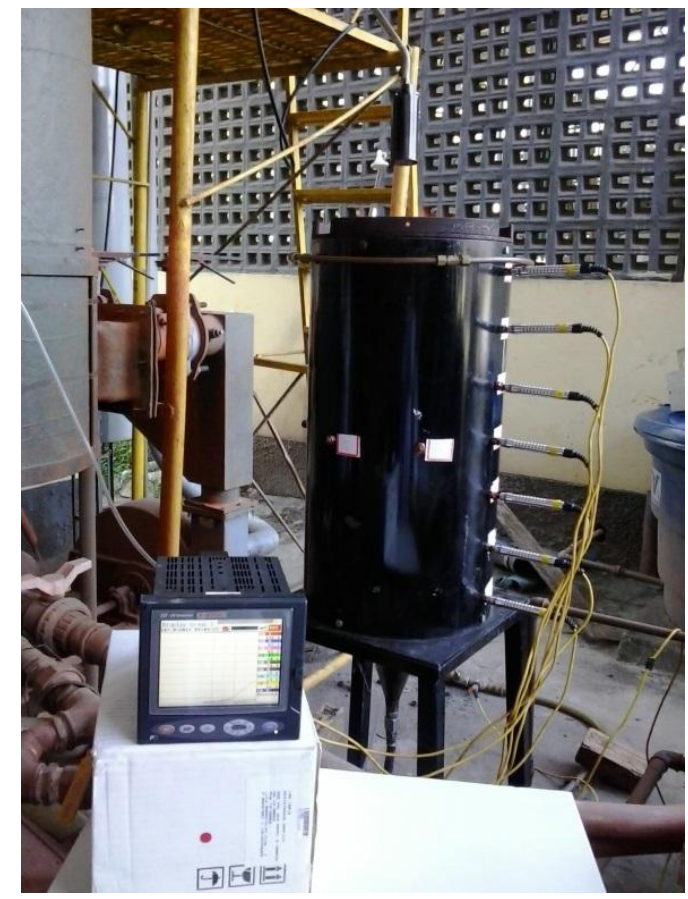

Figura 2- Reator vertical de leito fixo. 
Para o início do experimento, um maçarico acoplado a um botijão de gás GLP, executa a queima do gás e proporciona uma chama regulável, o qual é utilizado na parte superior do reator para dar ignição à combustão, definida para uma temperatura de $700^{\circ} \mathrm{C}$. Um ventilador é adaptado através de um tubo de cobre conectado a parte inferior do reator para succionar o ar, que contém o comburente da reação, promovendo assim o avanço da frente de combustão dentro do reator. A análise do avanço da frente de combustão e das temperaturas no interior do leito é feito através da medição de temperaturas em intervalos de tempo predeterminados utilizando-se termopares dispostos verticalmente no reator. A velocidade do ar foi medida através do termoanemômetro CFM.

No primeiro experimento a temperatura foi medida em termômetro digital portátil microprocessado (modelo Thermoind e marca Sensym) e sistema de aquisição de dados de temperatura Almemo 2290-8, respectivamente, a cada minuto em todos os termopares, enquanto que nos demais experimentos a aquisição dos dados de temperatura foi registrada no Paperless Recorder, tipo PHL a cada 5 segundos. Após a coleta de dados foi possível traçar um gráfico temperatura $\mathrm{x}$ tempo para analisar $\mathrm{o}$ avanço da frente de combustão $\mathrm{e} \mathrm{o}$ comportamento do perfil de temperatura de sinterização ao longo do leito.

\section{RESULTADOS PRELIMINARES E DISCUSSÃO}

Podemos observar que além da adição de carvão vegetal, biomassa utilizada na mistura para confecção dos corpos de provas que funciona como combustível sólido existe uma grande quantidade de carvão classificado que preenche $80 \%$ do reator, em todos os experimentos, o qual juntamente com o comburente presente no ar promove o processo de sinterização. A Tabela 2 apresenta os valores da velocidade do ar em todos os experimentos.

Tabela 2 - Velocidade do ar dentro do leito

\begin{tabular}{cc}
\hline Experimento & Velocidade do ar (m/s) \\
\hline 1 & 0,60 \\
2 & 0,51 \\
3 & 0,63 \\
4 & 0,55 \\
\hline
\end{tabular}

A Figura 3, a seguir, apresentam o gráfico resultante do experimento 1, o qual foi obtido sem a utilização do equipamento de aquisição de dados de temperatura, tipo PHL. 


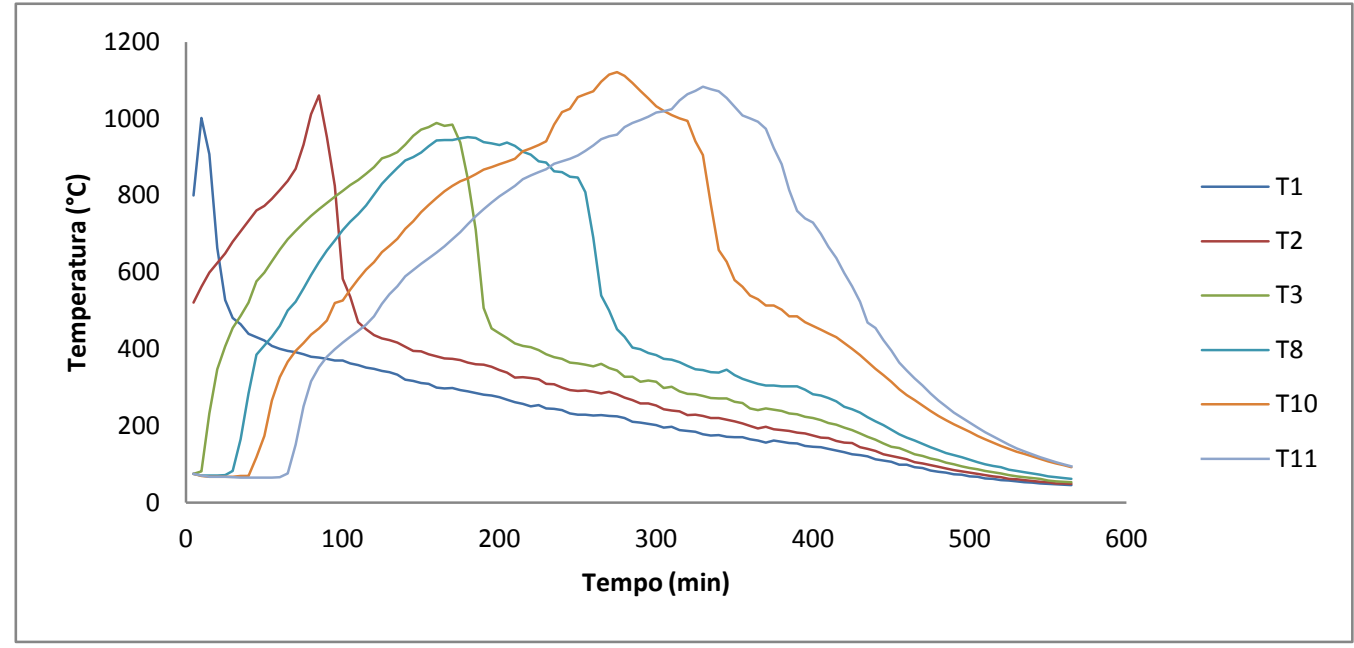

Figura 3 - Experimento 1.

Os perfis de temperatura apresentados na Figura 3 possuem aspectos semelhantes, em que a temperatura em cada termopar atingiu um valor máximo seguido de uma redução gradual, caracterizando o avanço da frente de combustão, sendo que a temperatura máxima alcançada de $1122^{\circ} \mathrm{C}$, entre os termopares, foi registrada em T5. Dentre as principais variáveis do processo: a granulometria (carvão e pelotas) e a velocidade do ar no leito, as quais foram responsáveis para que a frente de combustão seguisse gradativamente, resultaram no melhor desempenho deste experimento.

As Figuras 4, 5 e 6, a seguir, apresentam os gráficos resultantes dos experimentos 2, 3 e 4 respectivamente, os quais foram obtidos utilizando o equipamento de aquisição de dados de temperatura, tipo PHL.

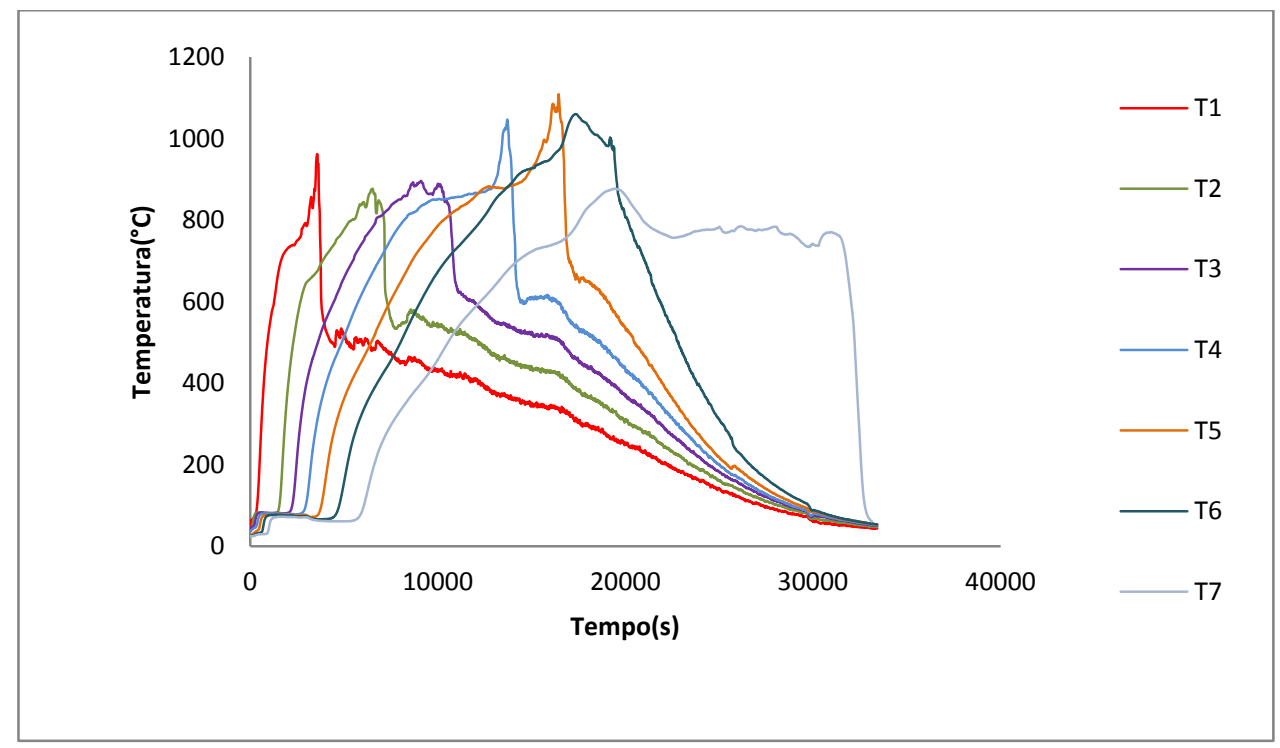

Figura 4 - Experimento 2. 


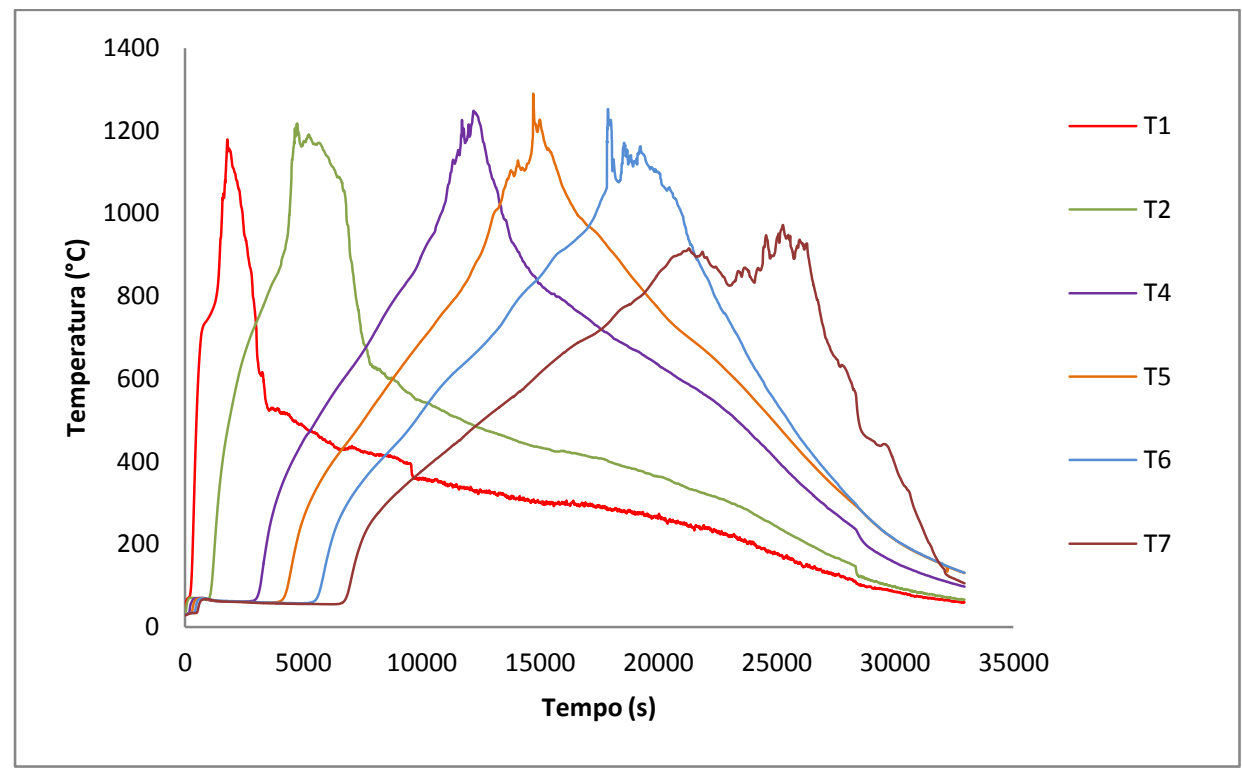

Figura 5 - Experimento 3.

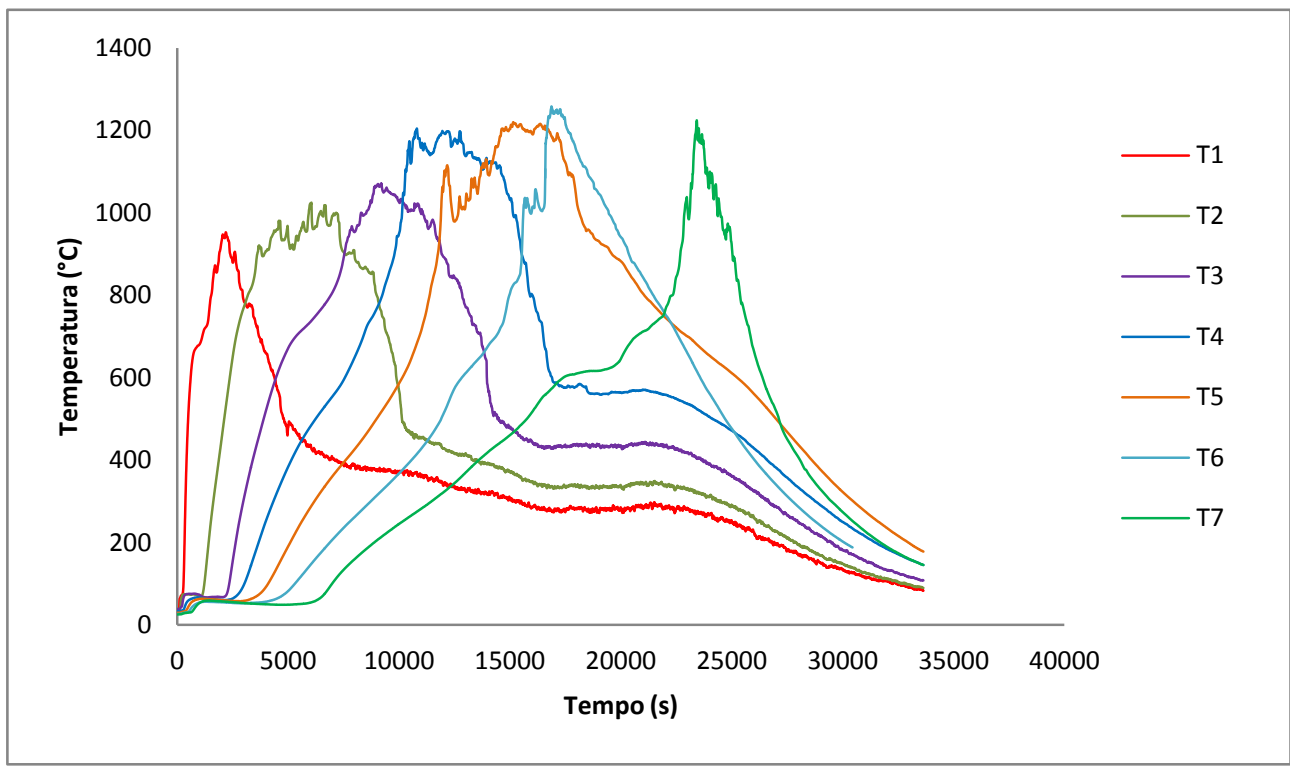

Figura 6 - Experimento 4.

Os gráficos apresentados nas Figuras 4, 5 e 6 apresentam perfis de temperatura semelhantes ao do experimento 1, comprovando que não houve estagnação da frente de combustão. As temperaturas máximas dos experimentos 2,3 e 4 foram respectivamente: $1085,3^{\circ} \mathrm{C}, 1288,5^{\circ} \mathrm{C}$ e $1239,8^{\circ} \mathrm{C}$. 


\section{CONCLUSÃO}

De acordo com os estudos preliminares houve o avanço da frente de combustão em todos os experimentos, onde o melhor resultado pode ser observado no experimento 3, no qual a velocidade do ar e a temperatura máxima foi maior. No entanto, há uma necessidade de novos testes para a obtenção da temperatura desejada (acima de $1250^{\circ} \mathrm{C}$ ao longo do leito), para garantir uma boa eficiência das reações de estado sólido e consequente formação da mulita, fase mineralógica que proporcionará propriedades cerâmicas satisfatórias. Vários parâmetros estão sendo testados para obtenção da temperatura de sinterização e consequente avanço mais controlado da frente de combustão. Entres os parâmetros que estão sendo testados temos a granulometria do carvão e das pelotas, composição das pelotas, quantidade de combustível sólido (biomassa) e velocidade do ar.

Desta forma a contribuição desse trabalho é com relação à capacidade que o material produzido tem em substituir agregados naturais, melhorando a qualidade do concreto e contribuindo para a preservação ambiental.

\section{REFERÊNCIAS BIBLIOGRAFICAS}

BRINDLEY, G. W., NAKAHIRA, M., 1958, "New concept of the transformation sequence of kaolinite to mullite", Nature, v. 181, pp. 1333-1334.

CABRAL, E. M., SÁ, R. J., VIEIRA, R. K., VASCONCELOS, R. P. Utilização de massas cerâmicas na produção de agregado sintético de argila calcinada para uso em concreto.Cerâmica, v. 54, pp 404-410.2008.

MARTINS, M.F.; Structure d'un front de combustion propagé en co-courant dansun lit fixe de schistebitumineuxbroyé, Doctorat de L'Université de Toulouse - L'Institut National Polytechnique de Toulouse - França; 2008.

MÖRTEL, H., HEIMSTADT, K., 1994, "Ceramics”, Werkstoffe und Korrosion-Materials and Corrosion, v. 45, pp. 128-136.

SOUZA SANTOS, P., Ciência e tecnologia de argilas. 2.ed. Edgard Blücher, 1989. 408 p. v. 1 .

TANCREDI, G. A. H. Estudo das propriedades do concreto com adição de cinza de carvão mineral de caldeiras de leito fluidizado.Dissertação (Mestrado)- 2010, Belém-PA. 